\title{
Posterior Coccygeoplasty for a Presacral Tumor
}

\author{
Geon Woo Oh, Sang Hyun Kim \\ Corresponding author: Sang Hyun Kim \\ Department of Neurosurgery, Ajou University Hospital, \\ Ajou University School of Medicine, 164, World Cup-ro, \\ Yeongtong-gu, Suwon 16499, Republic of Korea \\ Tel: $+82-31-219-5230$ \\ Fax: +82-31-219-5238 \\ E-mail: shkim709@aumc.ac.kr
}

Department of Neurosurgery, Ajou University Hospital, Ajou University School of Medicine, Suwon, Republic of Korea

Received: August 3, 2017

Revised: September 5, 2017

Accepted: September 8, 2017
Presacral tumor is an uncommon tumor and it has potential for malignant transformation. There are various surgical approaches in presacral tumor surgery. It depends on the size and position of tumor and if it has invaded surrounding organs. Posterior coccygeoplasty has several beneficial aspects for a patient with presacral tumor. It is easy to access to lower lying presacral mass and effective to maintain functions of coccyx. Coccygeoplasty can prevent surgery related injuries of anal sphincter and sacrum. We present a 24-year-old female patient that underwent resection of a presacral tumor through posterior coccygeoplasty and review pertinent literature.

Key Words: Sacrococcygeal Region; Pelvic neoplasms; Epidermal cyst

\section{INTRODUCTION}

The presacral tumor is an uncommon tumor and it has potential malignant transformation ${ }^{8,18)}$. Diagnosis is usually delayed because it presents clinical symptoms raised from affecting structures by compression of tumor mass in late period of tumor growth ${ }^{5,7)}$.

Posterior approach is preferred for small, benign lesions that do not extend above the level of the S2 vertebrae. The posterior approach is comprised of many techniques including the transsphincteric, transsacral, transrectal, transanorectal, and transsacrococcygeal approaches. Transcoccygeal approach only maintains anal sphincter and sacrum ${ }^{2)}$. It is easy to access to lower lying presacral mass. Coccygeoplasty can maintain functions of coccyx and prevent surgery related injuries of anal sphincter and sacrum.

We present a 24-year-old female patient that underwent resection of a presacral tumor through posterior coccygeoplasty and review pertinent literature.

\section{CASE REPORT}

A 24-year-old woman had been treated with medication because of acute pyelonephritis for 3 weeks without improvement. She underwent computed tomography (CT) scan and magnetic resonance imaging (MRI) for further evaluation that revealed a $6.3 \mathrm{~cm}$-sized high density non-enhancing cystic lesion in the presacral area. Ovaries and uterus were intact (Fig. 1). There was no evidence of adenopathy or metastatic disease within the abdominal cavity. Physical examination revealed normal sphincter tone, normal flexibility of perianal soft tissue, and an empty rectal vault with extrarectal fullness posteriorly reachable with the fingertip.

Posterior approach was conducted for total resection of tumor. Patient was placed in the prone jack-knife position with the buttocks spread (Fig. 2A). After an incision over the lower portion of the sacrum and coccyx down to the anus was conducted, the anococcygeal ligament was dissected and levator ani muscles were laterally retracted to obtain optimal surgical window approach to the presacral space (Fig. 2B). To provide good exposure, excision of the coccyx (coccygectomy) was necessary (Fig. 2C). Coccygotomy was conducted in a middle portion of coccyx because a part of bony coccyx should be retained for reconstruction of coccyx. Careful dissection was conducted to separate the tumor from the rectum and grossly total resection of tumor was conducted successfully (Fig. 2D). Reconstruction of coccyx was conducted using mini-profiled locking plates and monocortical (6 mm length; $2.4 \mathrm{~mm}$ diameter) locking screws (ARCH DePuy Synthes, Raynham, MA, USA). Bone dusts were packed into the bony cap between coccygec-
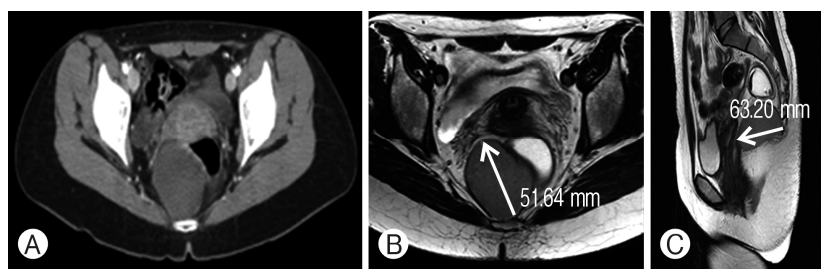

Fig. 1. (A) A $6.3 \mathrm{~cm}$ non-lobulated cyst with moderate signal intensity was shown on axial view of computed tomography scan image. Cystic mass was no definite enhancing portion on (B) axial and (C) sagittal views of abdomen/pelvic magnetic resonance image. 

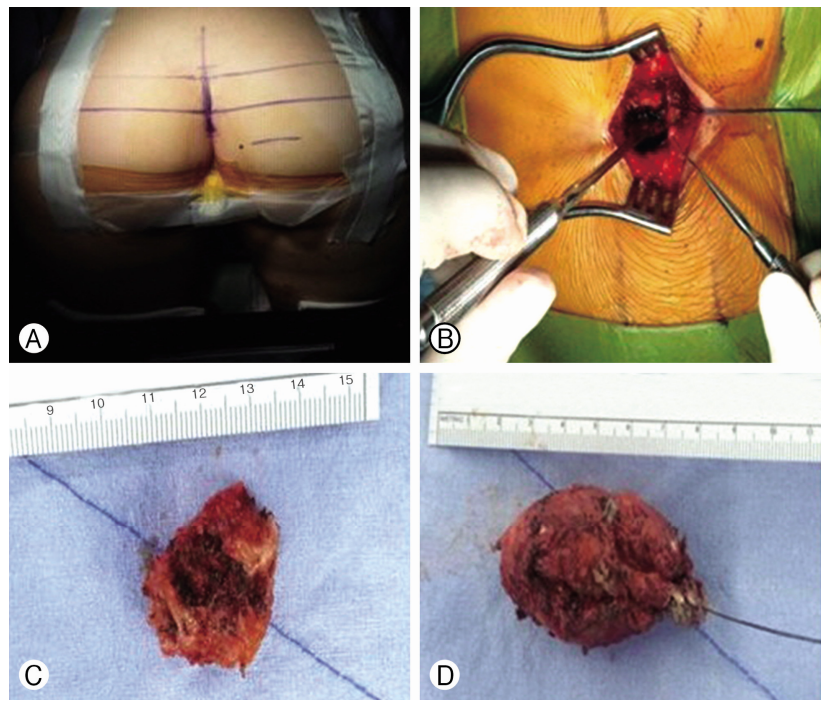

Fig. 2. (A) The operation was conducted in prone jack-knife position. (B) Incision was made on the lower portion of the sacrum and coccyx and $(C)$ coccyx was removed as a one piece after coccygotomy. (D) Total resection of tumor was conducted.

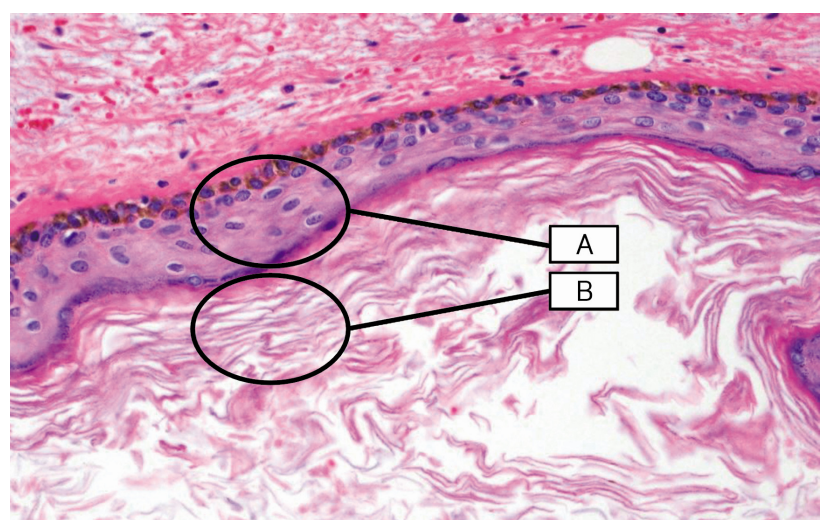

Fig. 3. Squamous epithelium (A) and lamellated keratin (B) were shown on the specimen slide image. Cystic cavity filled with lamellated keratin lined by a squamous epithelium $(H \& E, \times 200)$.

tomy bone flap and remained coccyx. Wound closure was completed after irrigation and meticulous hemostasis.

Pathologic diagnosis was confirmed as an epidermoid cyst (Fig. 3). Adequate reconstruction of the coccyx was revealed on postoperative 1-year follow-up X-ray image (Fig. 4).

\section{DISCUSSION}

The presacral tumor is an uncommon tumor and may grow larger or become a malignant tumor ${ }^{8,13,20)}$. About one-third of presacral tumors are congenital ${ }^{7,8,19)}$; neurogenic and osseous are approximately $10 \%$ respectively, and etc. ${ }^{8}$. Approximately $10 \%$ of teratoma are transformed into malignancy in a few years ${ }^{6,8)}$.
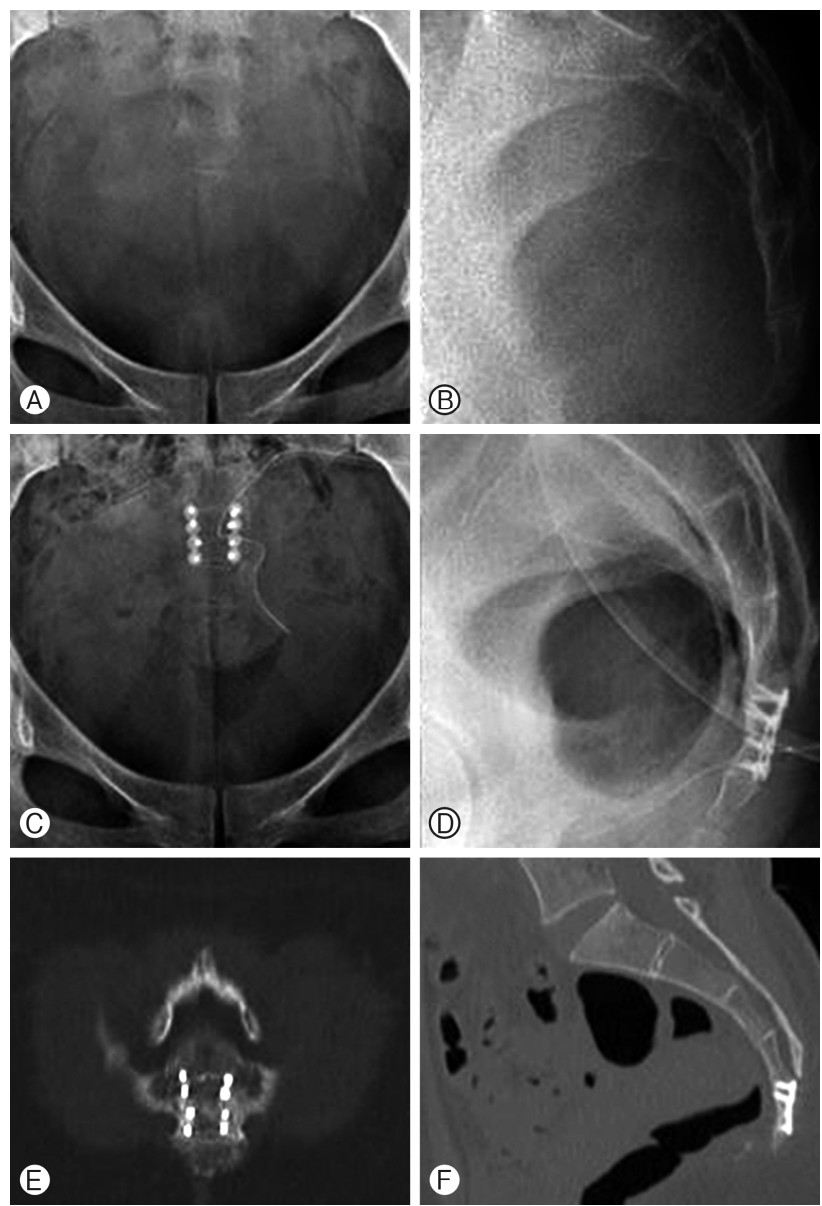

Fig. 4. (A, B) Preoperative and (C, D) postoperative sacrococcygeal $X$-rays are shown. (E, F) Solid bone fusion was confirmed on computed tomographic scan 1 year later after surgery.

Chordoma is most common solid retrorectal tumor ${ }^{3,4,7,8)}$.

The method of diagnosis is varied. CT and MRI are effective in finding the size and position of tumor, relative to surrounding organs as well as other pertinent information. Biopsy is recommended for tissue confirmation despite possibility of post-procedure infection $^{8)}$. In addition, it may be routes of proliferation of malignant tumor cells.

Presacral tumor occasionally reveals non-specific symptoms $^{3-5,8)}$ such as abdominal pain, bowel habit change, constipation, and inguinal area pain. This often makes a diagnosis complicated and may produce a wrong diagnosis $8,10,12,17,20$ ).

Surgical removal of presacral tumor is preferred for reducing infection, preventing malignant transformation, and making an accurate diagnosis ${ }^{15,21)}$.

Anterior and posterior surgical approaches may be applied for surgery of presacral tumor ${ }^{17)}$. Selection of surgical approach depends on the size and position of tumor and if it has invaded surrounding organs ${ }^{12)}$. The abdominal approach is usually conducted for these lesions that have their lowest extent above the level of the S4 vertebrae and do not have evidence of 
sacral involvement. Anterior approach is suitable for the tumor of upper sacral promontory ${ }^{20)}$. Laparoscopic approach to removing these tumors is a safe and feasible for a part of presacral tumors ${ }^{1,11)}$.

Posterior approach is preferred and familial for small, benign lesions that do not extend above the level of the S2 vertebrae ${ }^{2}$. The posterior approach is comprised of many techniques including the transsphincteric, transsacral, transrectal, transanorectal, and transsacrococcygeal approaches. Transcoccygeal approach only maintains anal sphincter and sacrum ${ }^{2}$. It is easy to access to lower lying presacral mass. But, transcoccygeal approach needs resection of coccyx. Coccygeoplasty can maintain functions of coccyx and prevent surgery related injuries of anal sphincter and sacrum.

Coccygotomy should be conducted in a middle portion of coccyx and a part of bony coccyx should be retained. Bone on bone fusion should be conducted for complete reconstruction of coccyx and final X-ray revealed stable reconstruction and bony fusion for this patient (Fig. 4).

Transsphincteric approach may cause sphincter deterioration $^{9,14,16)}$ and transsacral approach may cause hip discomfort and fistula ${ }^{11,20)}$. Even though posterior approaches cannot be entirely excluded from surgery related complications, coccygeoplasty has merits such as presacral organ protection, stability in sacrococcygeal area, and stable sitting position.

\section{CONCLUSION}

Posterior coccygeoplasty may be effective in maintaining bony structure, anal sphincter function, and preservation of coccyx for patients with lower lying presacral mass.

\section{CONFLICTS OF INTEREST}

No potential conflict of interest relevant to this article was reported.

\section{REFERENCES}

1. Bax NM, van der Zee DC: The laparoscopic approach to sacrococcygeal teratomas. Surg Endosc 18:128-130, 2004

2. Canessa CE: Dorsal transsacrococcygeal rectal approach. Dis Colon Rectum 48:1663-1665, 2005

3. Cody HS, 3rd, Marcove RC, Quan SH: Malignant retrorectal tumors: 28 years' experience at Memorial Sloan-Kettering Cancer Center. Dis Colon Rectum 24:501-506, 1981
4. Freier DT, Stanley JC, Thompson NW: Retrorectal tumors in adults. Surg Gynecol Obstet 132:681-686, 1971

5. Glasgow SC, Birnbaum EH, Lowney JK, Fleshman JW, Kodner IJ, Mutch DG, et al.: Retrorectal tumors: a diagnostic and therapeutic challenge. Dis Colon Rectum 48:1581-1587, 2005

6. Head HD, Gerstein JD, Muir RW: Presacral teratoma in the adult. Am Surg 41:240-248, 1975

7. Hobson KG, Ghaemmaghami V, Roe JP, Goodnight JE, Khatri VP: Tumors of the retrorectal space. Dis Colon Rectum 48: 1964-1974, 2005

8. Jao SW, Beart RW, Jr., Spencer RJ, Reiman HM, Ilstrup DM: Retrorectal tumors. Mayo Clinic experience, 1960-1979. Dis Colon Rectum 28:644-652, 1985

9. Kanemitsu T, Kojima T, Yamamoto S, Koike A, Takeshige K, Naruse T: The trans-sphincteric and trans-sacral approaches for the surgical excision of rectal and presacral lesions. Surg Today 23:860-866, 1993

10. Kolodziejski LS, Dyczek ST, Pogodzinski M: [Surgical management of retrorectal tumors]. J Chir (Paris) 141:109-113, 2004

11. Konstantinidis K, Theodoropoulos GE, Sambalis G, Georgiou M, Vorias M, Anastassakou K, et al.: Laparoscopic resection of presacral schwannomas. Surg Laparosc Endosc Percutan Tech 15:302-304, 2005

12. Lev-Chelouche D, Gutman M, Goldman G, Even-Sapir E, Meller I, Issakov J, et al.: Presacral tumors: a practical classification and treatment of a unique and heterogeneous group of diseases. Surgery 133:473-478, 2003

13. Lovelady SB, Dockerty MB: Extragenital pelvic tumors in women. Am J Obstet Gynecol 58:215-236, 1949

14. Meissner K, Jirikowski B, Szecsi T: Mason paracoccygeal transsphincteric approach to the rectum: good outcome only in highly selective indications? Chirurg 67:145-149, 1996

15. Pappalardo G, Frattaroli FM, Casciani E, Moles N, Mascagni D, Spoletini D, et al.: Retrorectal tumors: the choice of surgical approach based on a new classification. Am Surg 75:240-248, 2009

16. Pescatori M, Brusciano L, Binda GA, Serventi A: A novel approach for perirectal tumours: the perianal intersphincteric excision. Int J Colorectal Dis 20:72-75, 2005

17. Singer MA, Cintron JR, Martz JE, Schoetz DJ, Abcarian H: Retrorectal cyst: a rare tumor frequently misdiagnosed. J Am Coll Surg 196:880-886, 2003

18. Spencer RJ, Jackman RJ: Surgical management of precoccygeal cysts. Surg Gynecol Obstet 115:449-452, 1962

19. Uhlig BE, Johnson RL: Presacral tumors and cysts in adults. Dis Colon Rectum 18:581-589, 1975

20. Wolpert A, Beer-Gabel M, Lifschitz O, Zbar AP: The management of presacral masses in the adult. Tech Coloproctol 6:43-49, 2002

21. Woodfield JC, Chalmers AG, Phillips N, Sagar PM: Algorithms for the surgical management of retrorectal tumours. Br J Surg 95:214-221, 2008 